\title{
Probiotic effect of Lactococcus lactis subsp. cremoris RPG-HL-0136 on intestinal mucosal immunity in mice
}

\author{
Byoung Hee Park ${ }^{1,2,3}$, In Sung Kim², Jung Kuk Park ${ }^{4}$, Zheng Zhi ${ }^{5}$, Hea Min Lee ${ }^{1}$, Oh Wook Kwon ${ }^{2}$ and \\ Byung Cheon Lee ${ }^{1 *}$ (D)
}

\begin{abstract}
Lactococcus lactis subsp. cremoris is a lactic acid bacterium commonly used in the cheese manufacturing industry. It is known to produce antibacterial peptides and has recently received attention for its role as a probiotic strain. Here, we report the isolation of a new strain, Lactococcus lactis subsp. cremoris RPG-HL-0136 (RPG0136) from dried compost, which exhibits strong antibacterial activity. When RPG0136 was fed to mice, it increased the intestinal population of two beneficial bacteria, Lactobacillus and Bifidobacterium, whereas it decreased the intestinal population of two harmful bacteria, Bacteroides and Enterobacter. In addition, it increased the concentration of short-chain fatty acids, including acetic acid, propionic acid, and butyric acid, with a simultaneous decrease in $\mathrm{pH}$, and accelerated the catabolic degradation of proteins, lipids, and starch. Lastly, RPG0136 increased the plasma lgG and intestinal mucosal SIgA concentrations and upregulated Reg3r, MUC1, and MUC2 expression to improve the intestinal mucosal immune function. The results of this study suggest that RPG0136 is a potential probiotic strain that supports the growth of a beneficial microbiome by promoting the synthesis of organic acids and enhancing intestinal immune function.
\end{abstract}

Keywords: Lactococcus lactis subsp. cremoris, Intestinal mucosal immunity, Microbiome, Probiotics

\section{Introduction}

The intestine is a major site for the digestion and absorption of nutrients and is colonized by various microorganisms [1]. Numerous studies have reported that the intestinal microflora not only regulates the nutrient metabolites of the host, but also interacts with the host immune system and influences the progression of diseases [2]. For example, external stimuli, such as excessive food or drugs, disturb the intestinal environment and cause an imbalance in the population of intestinal symbiotic microorganisms that affect metabolite production and host immunity, such as Lactobacillus, Enterococcus, and Streptococcus, and Enterobacteria; this may lead to

\footnotetext{
*Correspondence: cheonii@korea.ac.kr

${ }^{1}$ Department of Biotechnology, College of Life Sciences

and Biotechnology, Korea University, Seoul 02841, Republic of Korea

Full list of author information is available at the end of the article
}

the development of diabetes, fatty liver, obesity, and other diseases [3-7].

Lactococcus lactis is a gram-positive lactic acid bacterium widely used to coagulate milk in the cheese and butter industry, and its use has been approved owing to its designation as a generally recognized as safe bacterium. It is known to produce bacteriocins, such as nisin, which exert cationic antibacterial peptide activity in metabolic processes $[8,9]$. Nisin contains dehydrated amino acid residues (serine and threonine) and a thioether amino acid that forms five lanthionine rings, which are characteristic of lantibiotics $[10,11]$. As a food bio-preservative, nisin acts as a broad-spectrum bacteriocin against most gram-positive food-borne bacteria [12-14].

We identified a new strain of Lactococcus lactis subsp. cremoris from dried compost based on its morphological characteristics and antibacterial activity. The interaction of the strain with the symbiotic intestinal 
microbiome and its effects on intestinal immunity and nutrient metabolites in mouse were investigated.

\section{Materials and methods Isolation of microorganism}

Dried compost was collected from EumSeong in ChungBuk, Korea. More than 100 bacterial strains were screened from the compost based on their morphological characteristics. Among these, the strain that showed the strongest antibacterial activity against Micrococcus luteus ATCC10240 was isolated. After 16S rRNA sequencing, it was identified as a new strain of Lactococcus lactis subsp. cremoris, named Lactococcus lactis subsp. cremoris RPGHL-0136, and submitted for preservation at the Korean Culture Center of Microorganisms (KCCM, Seoul, Korea). Micrococcus luteus ATCC10240 used for screening was purchased from the Korean Culture Center of Microorganisms (KCCM). These bacteria were cultured in NB medium (BD Difco Co., Ltd., MD, USA) at $26^{\circ} \mathrm{C}$ for $24 \mathrm{~h}$. The culture medium was centrifuged at $8,000 \mathrm{rpm}$ $(6,910 \mathrm{~g})$ for $10 \mathrm{~min}$ at $4{ }^{\circ} \mathrm{C}$, and the supernatant was discarded. The bacteria were then washed twice with saline, and the OD value of the suspension was adjusted to form the low-dose group $\left(1 \times 10^{8} \mathrm{CFU} / \mathrm{ml}\right)$ and high-dose group $\left(1 \times 10^{10} \mathrm{CFU} / \mathrm{ml}\right)$.

\section{Animals}

Six-week-old BALB/c mice housed in a specific pathogen-free-grade facility were obtained from Orient Bio Inc. Korea. The adaptation period lasted for 2 weeks before the experiment. The mice were randomly categorized into three groups: control, low-dose, and high-dose (10 mice in each group). The bacterial suspension was freshly prepared each day for low-dose and high-dose group according to the method mentioned above and orally administered to the mice at $1 \mathrm{ml} /$ day for 30 days. After 30 days, the intestinal tissue, blood samples, and feces samples were collected for analysis. The excreted feces from these mice were collected four times per day for 30 days. The feces sample was prepared by removing foreign substances, and their weights were recorded before analysis. All animal experiments were approved by the Institutional Animal Care and Use Committee of Korea University (KUIACUC-2021-0002), and all animals were cared for properly according to the guidelines.

\section{Culture of intestinal bacteria}

After the mice were sacrificed, the microbes were isolated from the non-excreted feces and cultured on selective media using the plate count method. Lactobacillus was cultured in Lactobacillus Selection medium (BD Difco Co., Ltd.) $[15,16]$, and Bifidobacterium was cultured on Bifidobacterium selective agar medium (BD
Difco Co., Ltd.) [15]. Bacteroides were cultured in Gifu Anaerobic Medium (KisanBio Co., Ltd., Seoul, Korea) [17], and Enterobacter were cultured in Eosin Methylene Blue Agar Medium (KisanBio Co., Ltd.,) $[18,19]$. The bacteria were cultured at $37{ }^{\circ} \mathrm{C}$ for $48 \mathrm{~h}$ under anaerobic conditions, and the number of colony-forming units was counted using the plate counting method.

\section{Measurement of $\mathrm{pH}$ and acetic acid, propionic acid, and butyric acid concentrations}

Fresh feces $(2 \mathrm{~g})$ was dissolved in $20 \mathrm{ml}$ of distilled water, and the $\mathrm{pH}$ was measured using a $\mathrm{pH}$ meter (STARTER 3100, OHAUS, Parsippany, NJ, USA). Additionally, fresh feces $(0.5 \mathrm{~g})$ was dissolved in $1 \mathrm{ml}$ of distilled water and incubated for $3 \mathrm{~h}$. After centrifugation at 12,000 rpm $(15,547 \mathrm{~g})$ for $10 \mathrm{~min}$ at $4{ }^{\circ} \mathrm{C}$, the supernatant was collected and filtered using a $0.22 \mu \mathrm{m}$ membrane filter. The concentrations of acetic acid, propionic acid, and butyric acid were measured using high-performance liquid chromatography (HPLC, Waters e2695 HPLC, photodiode array detector, Milford, MA, USA). An Inno column (C18 $4.6 \mathrm{~mm}$ ID $\times 250 \mathrm{~mm} \mathrm{~L}$; YoungJin Biochrom Co., Ltd. Korea) was used for the analysis. For the mobile phase, $20 \mathrm{mM} \mathrm{NaH}_{2} \mathrm{PO}_{4}$ (pH 2.7) was used.

\section{Measurement of $\mathrm{H}_{2} \mathrm{~S}$ and $\mathrm{NH}_{3}$ concentrations}

An Alka-Seltzer tablet was placed in $100 \mathrm{ml}$ of the fecal suspension and allowed to stand for $2 \mathrm{~min}$. Then, the $\mathrm{H}_{2} \mathrm{~S}$ concentration was measured using an $\mathrm{H}_{2} \mathrm{~S}$ detection kit (Model HS-C, HACH, Ames, IA, USA). Ammonia salicylate was added to $5 \mathrm{ml}$ of the fecal suspension and allowed to react for $3 \mathrm{~min}$. Ammonia cyanurate was then added and allowed to react for $15 \mathrm{~min}$. After the color of the suspension changed to green, the $\mathrm{NH}_{3}$ concentration was measured using a color comparator box (Model NI-SA, HACH).

\section{Rate of metabolic degradation of nutrients}

The fecal suspension (1\%) and starch (5\%) were added to MRS medium (BD Difco Co., Ltd.), followed by anaerobic culture at $37{ }^{\circ} \mathrm{C}$ for $24 \mathrm{~h}$. Next, $1 \mathrm{ml}$ of the culture medium containing fecal bacteria was mixed with $1 \mathrm{ml}$ of ethanol and $5 \mathrm{ml}$ of $1 \mathrm{M} \mathrm{NaOH}$ and incubated for $24 \mathrm{~h}$. After this, the medium was boiled for $10 \mathrm{~min}$ and mixed with $43 \mathrm{ml}$ of distilled water and $1 \mathrm{ml}$ of a mixed solution ( $1 \mathrm{M}$ acetic acid, $0.2 \mathrm{~g}$ iodine, $2 \mathrm{~g}$ potassium iodide, and $250 \mathrm{ml}$ of water). After incubation at $30{ }^{\circ} \mathrm{C}$ for $20 \mathrm{~min}$, the OD value was measured at $620 \mathrm{~nm}$ using a spectrophotometer for estimating starch degradation. Next, the $1 \%$ fecal suspension and $2 \%$ soybean oil were added to the MRS medium (BD Difco Co., Ltd.), followed by anaerobic culture at $37{ }^{\circ} \mathrm{C}$ for $24 \mathrm{~h}$. After dichloromethane was added to dissolve the insoluble oil components, 
the OD value was measured at $420 \mathrm{~nm}$ using a spectrophotometer to estimate lipid degradation. The $1 \%$ fecal suspension and $1 \%$ ovalbumin were added to the MRS medium (BD Difco Co., Ltd.) and cultured anaerobically at $37^{\circ} \mathrm{C}$ for $24 \mathrm{~h}$. The ovalbumin concentration was then measured using a microplate reader to estimate protein degradation.

\section{Measurement of mouse plasma IgG and intestinal mucosal} secretory $\lg \mathrm{A}(\mathrm{S} \lg \mathrm{A})$ concentrations

Intestinal tissue and feces were collected from the mice, and blood was collected from the inferior vena cava. The blood was then centrifuged at $5000 \mathrm{rpm}$ for $5 \mathrm{~min}$ at $4{ }^{\circ} \mathrm{C}$ to collect the plasma. The plasma IgG concentration was measured using a mouse IgG ELISA kit (R\&D Systems, Minneapolis, MN, USA). To measure the SIgA concentration, $5 \mathrm{ml}$ of PBS buffer was used to wash the intestinal tissue at room temperature and then centrifuged at $13,000 \mathrm{rpm}$ at $4{ }^{\circ} \mathrm{C}$ for $10 \mathrm{~min}$. The supernatant was collected to measure the SIgA concentration using a mouse SIgA ELISA kit (QuickDetect, BioVision Inc., CA, USA). A microplate reader (iMark; Bio-Rad Laboratories, Inc., Hercules, CA, USA) was used for both measurements.

\section{Analysis of mRNA expression using qRT-PCR}

The mRNA expression levels of TNF- $\alpha$, IL-1ß, IL-6, IL-12, Reg3r, MUC1, and MUC2 genes in the intestinal tissues were measured. After mRNA was extracted from the intestinal tissues using a universal RNA extraction kit (Bioneer Co., Ltd., Daejeon, Korea) and an automated nucleic acid extractor (ExiPrep 16 plus, Bioneer Co., Ltd.), the mRNA expression levels were analyzed using qRT-PCR (Exicycler TM 96 V4 Real-Time qPCR, Bioneer Co., Ltd.). The primer sequences for the genes are shown in Table 1.

\section{Statistical analysis}

Statistical analysis was performed using Student's $t$-test and one-way analysis of variance, and the program used was Prism. Differences were considered statistically significant at $\mathrm{p}<0.05$.

\section{Results}

Isolation and characterization of Lactococcus lactis subsp. cremoris RPG-HL-0136

More than 100 strains were isolated from the dried compost based on morphological characteristics. The new strain, isolated using the well diffusion method, showed strongest antibacterial activity against Micrococcus luteus ATCC10240. Based on the 16S rRNA sequencing and phylogenetic diagram, this strain was identified as Lactococcus lactis subsp. (Fig. 1). This strain was named Lactococcus lactis subsp. cremoris RPG-HL-0136 (RPG0136)
Table 1 Primers used for quantitative real-time polymerase chain reaction

\begin{tabular}{ll}
\hline & Sequence $\mathbf{( 5}^{\prime} \mathbf{- 3}^{\mathbf{\prime}} \mathbf{)}$ \\
\hline TNF-a & CCTGTAGCCCACGTCGTAG \\
& GGGAGTAGACAAGGTACAACCC \\
IL-6 & TACCACTTCACAAGTCGGAGGC \\
& CTGCAAGTGCATCATCGTTGTC \\
IL-1ß & TGGACCTTCCAGGATGAGGACA \\
& GTTCATCTCGGAGCCTGTAGTG \\
IL-12 & ACGAGAGTTGCCTGGCTACTAG \\
& CCTCATAGATGCTACCAAGGCAC \\
Reg3r & CCGTGCCTATGGCTCCTATTG \\
MUC1 & GCACAGACACAAGATGTCCTG \\
& GATGTTCTGTCTCCCTCCTCTG \\
MUC2 & CACTCATGGGGGGTAGGTATC \\
& CCGTCCTCATACCACATC \\
& CCTGAAGTCATCGCTCTC
\end{tabular}

and preserved by the Korean Culture Center of Microorganisms (KCCM, Seoul, Korea). The optimum growth conditions for RPG0136 were observed at $26{ }^{\circ} \mathrm{C}$ and $\mathrm{pH}$ 7.4 .

\section{Effect of RPG0136 on the intestinal microbiome}

The maintenance of intestinal health depends on the composition of beneficial and harmful intestinal microbiome. To determine the effects of RPG0136 on the population of beneficial and harmful microorganisms, RPG0136 or no bacteria were orally administered to mice, and the number of colonies formed by intestinal Lactobacillus, Bifidobacterium, Bacteroides, and Enterobacter were counted by culture on selective media using the plate counting method (Fig. 2). The counts of Lactobacillus and Bifidobacterium increased and the counts of Bacteroides and Enterobacter decreased after the administration of RPG0136 at both low $\left(1 \times 10^{8} \mathrm{CFU} / \mathrm{ml}\right)$ and high $\left(1 \times 10^{10} \mathrm{CFU} / \mathrm{ml}\right)$ concentrations. The findings indicated that the RPG0136 strain effectively increased the population of beneficial gut bacteria and decreased the population of harmful gut bacteria.

\section{Changes in short-chain fatty acid (SCFA) concentrations and $\mathrm{pH}$ induced by RPG0136}

SCFAs, primarily produced during intestinal bacterial metabolism, play a crucial role in the maintenance of intestinal health as well as overall heath by inducing an acidic environment. After RPG0136 administration, the concentrations of acetic acid, propionic acid, and butyric acid and the $\mathrm{pH}$ were measured in the mouse fecal samples (Fig. 3). The concentrations of the three SCFAs increased in the mice fed RPG0136. In particular, the 
A

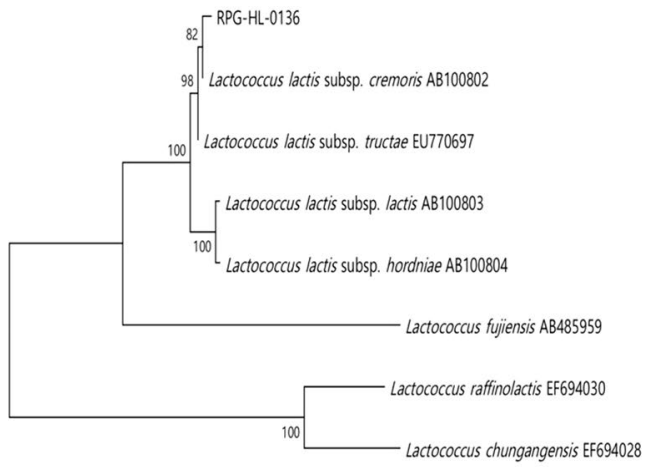

B

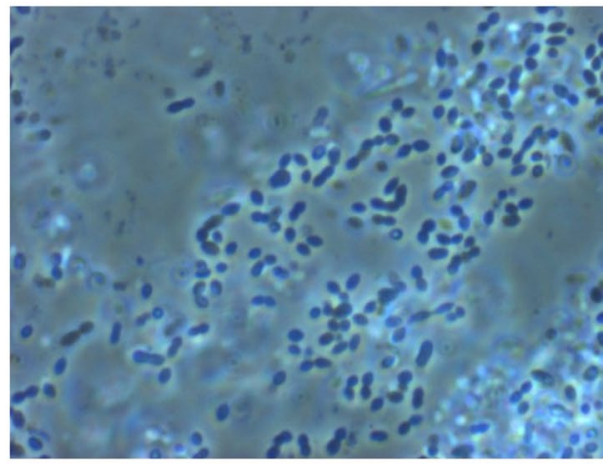

0.0100

Fig. 1 Identification of RPG0136. A Phylogenetic diagram showing the relationship between close strains identified through 16S rRNA sequencing. B Image showing the morphological characteristics of RPG0136

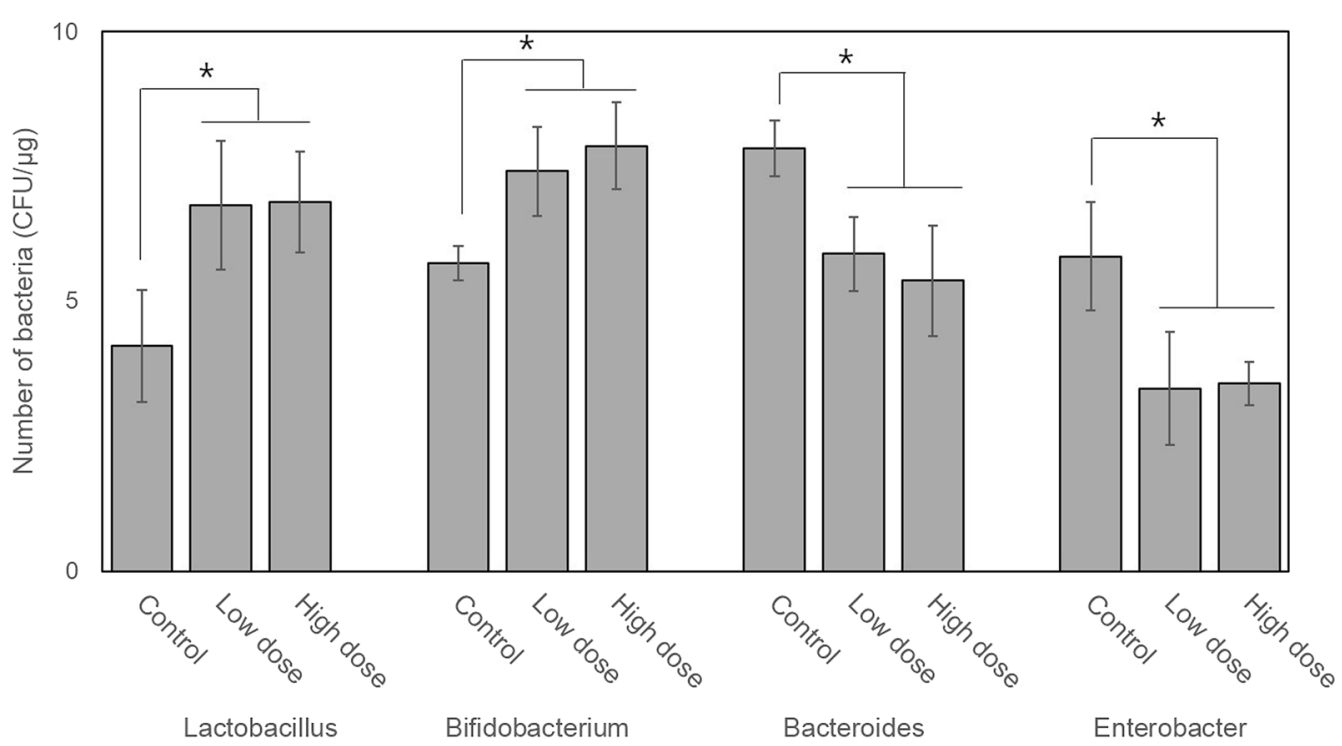

Fig. 2 Effect of RPG0136 treatment on intestinal bacteria. The counts of Lactobacillus, Bifidobacterium, Bacteroides, and Enterobacter in the mouse intestine after the oral administration of RPG0136 (low-dose: $1 \times 10^{8}$ colony-forming units (CFU)/ml; high-dose: $1 \times 10^{10} \mathrm{CFU} / \mathrm{ml}$ ) were determined. Data are presented as the average value of the results of four independent experiments with standard deviations, ${ }^{*} \mathrm{p}<0.05$

concentration of acetic acid increased more drastically depending on the RPG0136 concentration. Moreover, the administration of RPG0136 was associated with a decrease in $\mathrm{pH}$. These findings indicated that RPG0136 increased the production of the three SCFAs (as metabolites of the microbiome) and decreased the $\mathrm{pH}$.

\section{Reduction of $\mathrm{NH}_{3}$ and $\mathrm{H}_{2} \mathrm{~S}$ production by $\mathrm{RPG} 0136$}

The intestinal microbiome catabolizes dietary proteins and produces small toxic molecules, such as $\mathrm{H}_{2} \mathrm{~S}$ and $\mathrm{NH}_{3}$. The $\mathrm{H}_{2} \mathrm{~S}$ and $\mathrm{NH}_{3}$ concentrations were measured in the fecal samples of mice fed RPG0136 (Fig. 4). Compared to that in control mice, the $\mathrm{H}_{2} \mathrm{~S}$ and $\mathrm{NH}_{3}$ concentrations decreased in mice fed RPG0136 at low concentrations as well as in mice fed RPG0136 at high concentrations. Therefore, the reduction in the population of harmful bacteria may be associated with decreased $\mathrm{H}_{2} \mathrm{~S}$ and $\mathrm{NH}_{3}$ production.

\section{Rate of metabolic degradation of nutrients}

RPG0136 enhanced the production of SCFAs as metabolites produced by the intestinal microbiome. We also 
A

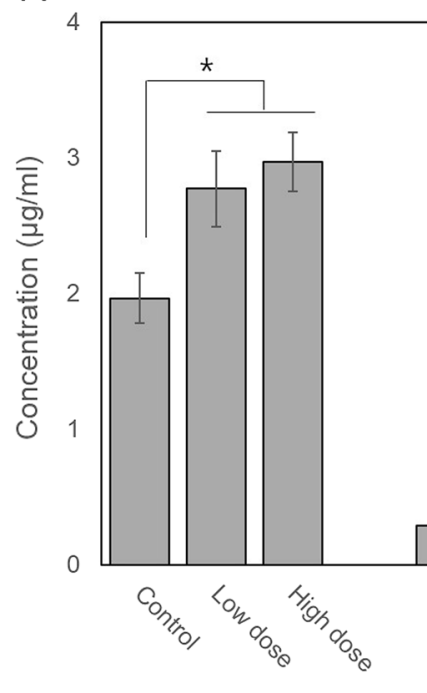

Acetic Acid

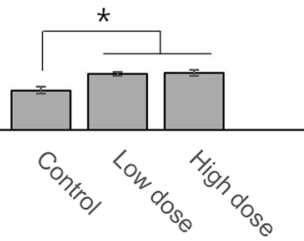

Propionic Acid
B

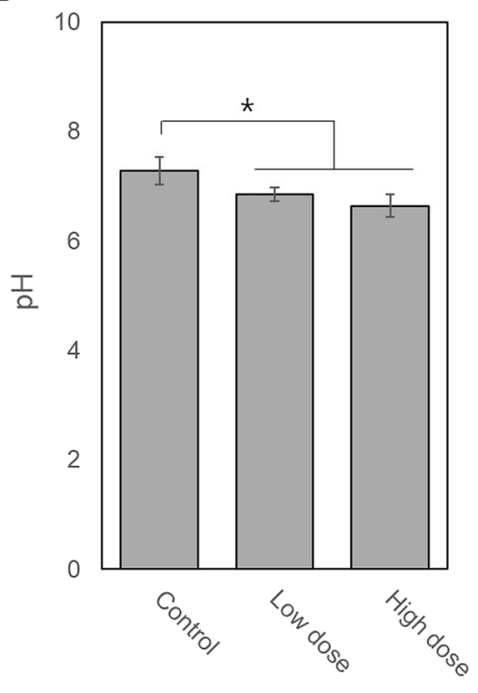

Fig. 3 Intestinal concentration of short-chain fatty acids (SCFAs) and the intestinal $\mathrm{pH}$. $\mathbf{A}$ Intestinal concentration of SCFAs, including acetic acid, propionic acid, and butyric acid; B pH was measured after the oral administration of RPG0136 (low-dose: $1 \times 10^{8}$ colony-forming units (CFU)/ml; high-dose: $\left.1 \times 10^{10} \mathrm{CFU} / \mathrm{ml}\right)$. Data are presented as the average value of the results of four independent experiments with standard deviations, ${ }^{*} p<0.05$

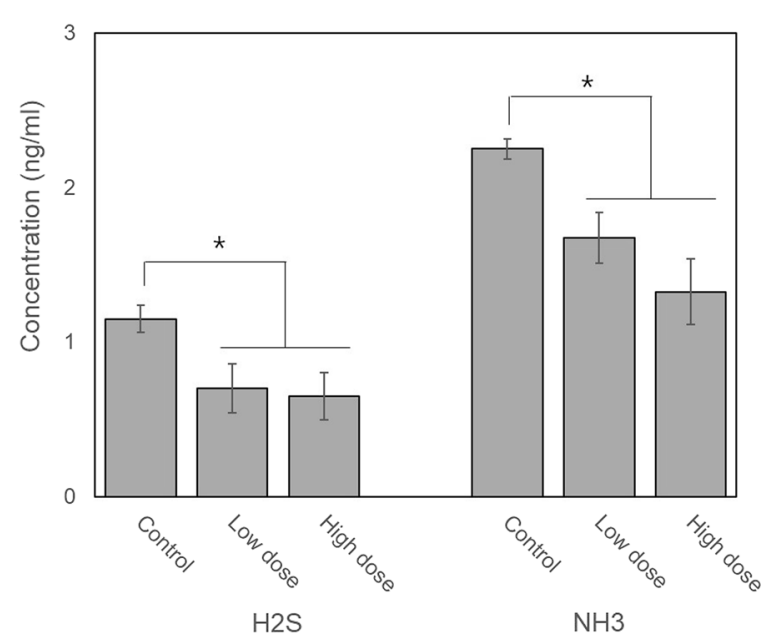

Fig. $4 \mathrm{H}_{2} \mathrm{~S}$ and $\mathrm{NH}_{3}$ concentrations in mouse feces. The concentrations of $\mathrm{H}_{2} \mathrm{~S}$ and $\mathrm{NH}_{3}$ in mouse fecal samples were measured after the oral administration of RPG0136 (low-dose: $1 \times 10^{8}$ colony-forming units (CFU)/ml; high-dose: $\left.1 \times 10^{10} \mathrm{CFU} / \mathrm{ml}\right)$. Data are presented as the average value of the results of four independent experiments with standard deviations, ${ }^{*} p<0.05$

evaluated the metabolic degradation rate of other nutrients, including starch, lipids, and proteins, produced by the fecal microbiome (Fig. 5). Interestingly, compared to that in the control group, the metabolic degradation of all three nutrients increased in a dose-dependent manner upon RPG0136 administration. This finding indicated that RPG0136 enhances the biological activity of the microbiome to promote the metabolic degradation of starch, lipids, and proteins, besides increasing the production of SCFAs.

\section{Enhanced intestinal mucosal immune function in mouse fed RPG0136}

To assess changes in the immune response of mice fed RPG0136, the plasma IgG (for humoral immunity) and intestinal mucosal SIgA (for intestinal mucosal immunity) concentrations were analyzed (Fig. 6). Interestingly, both IgG and SIgA levels increased upon feeding with RPG0136. This implies that RPG0136 enhanced the mouse immune function against potentially harmful antigens and pathogenic bacteria, especially in the intestinal mucosa.

Next, the mRNA levels of the pro-inflammatory cytokines TNF- $\alpha$, IL- 6 , IL-1ß, and IL-12 and of genes encoding Reg3r, MUC1, and MUC2 (which confer congenital intestinal mucosal immunity) were analyzed to assess immune response regulation (Fig. 7). The mRNA expression of TNF- $\alpha$, IL-6, IL-1ß, and IL-12 did not change, but the mRNA expression of Reg3r, MUC1, and MUC2 increased with RPG0136 administration. Therefore, RPG0136 enhanced the intestinal mucosal immune function by increasing the plasma IgG and intestinal mucosal SIgA concentrations. 


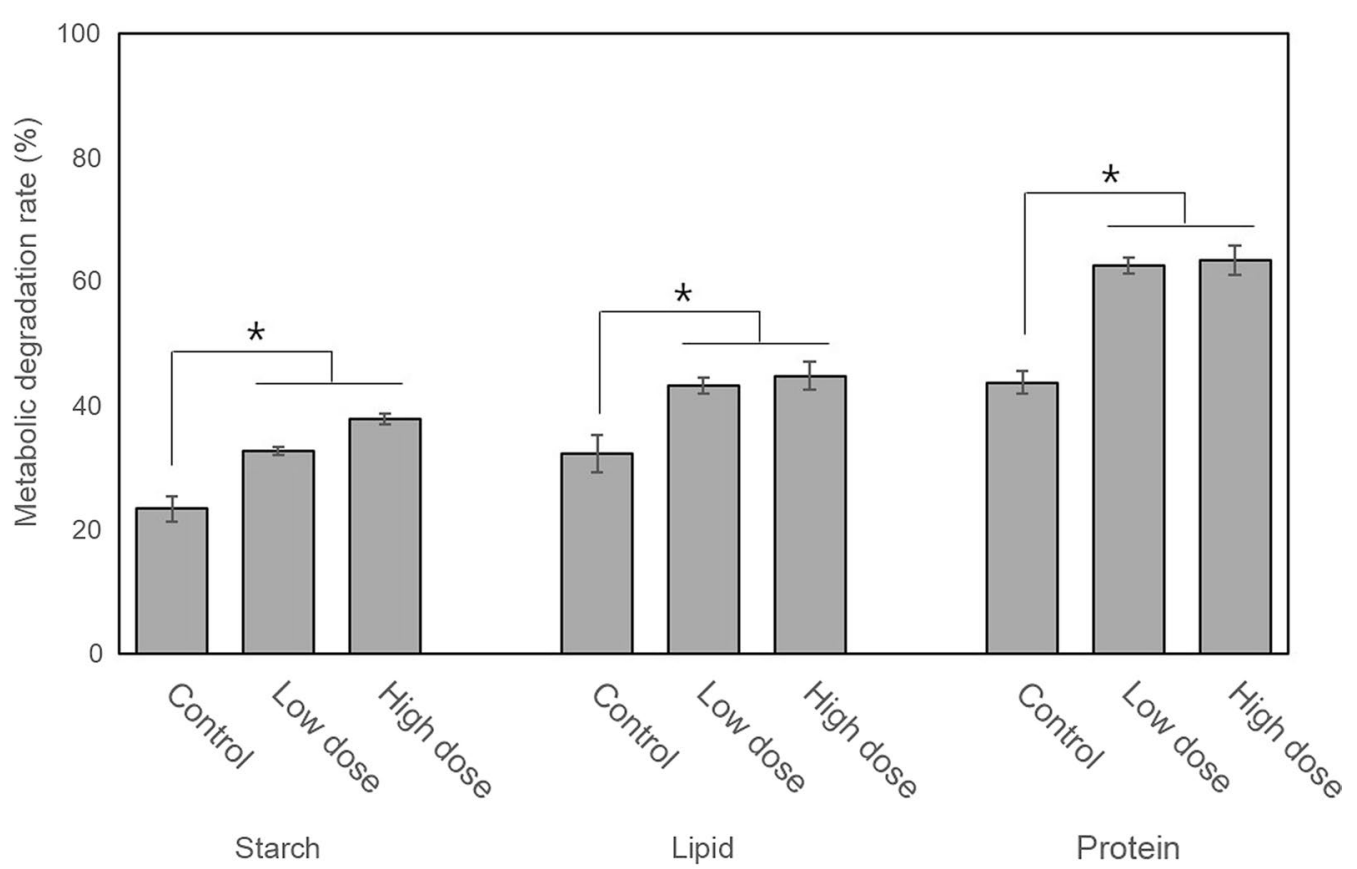

Fig. 5 Rate of metabolic degradation of nutrients by fecal bacteria. Starch, lipid, and protein were incubated with fecal bacteria obtained from mouse after the oral administration of RPG0136 (low-dose: $1 \times 10^{8}$ colony-forming units (CFU)/ml; high-dose: $1 \times 10^{10} \mathrm{CFU} / \mathrm{ml}$ ), and the rate of metabolic degradation of the nutrients was analyzed. Data are presented as the average value of the results of four independent experiments with standard deviations, ${ }^{*} \mathrm{p}<0.05$

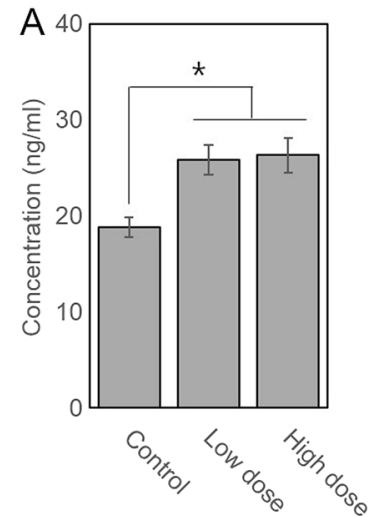

$\lg G$

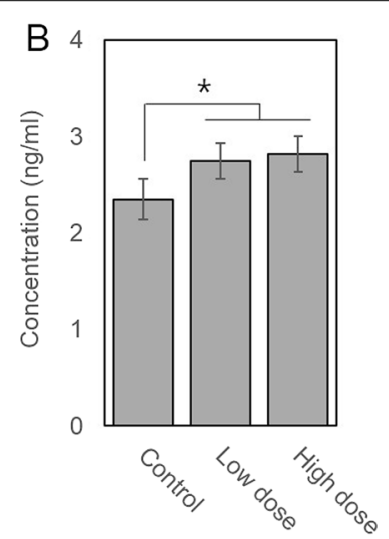

SIgA
Fig. 6 Plasma lgG and intestinal mucosal SlgA concentrations. A Plasma IgG and $\mathbf{B}$ intestinal mucosal SIgA concentrations were measured in mouse after the oral administration of RPG0136 (low-dose: $1 \times 10^{8}$ colony-forming units (CFU)/ml; high-dose: $1 \times 10^{10} \mathrm{CFU} / \mathrm{ml}$ ). Data are presented as the average value of the results of four independent experiments with standard deviations, ${ }^{*} p<0.05$

\section{Discussion}

The probiotic effect of strain RPG0136 promoted the dominance of two beneficial bacteria,
Lactobacillus and Bifidobacterium, which increased the concentration of the SCFAs acetic acid, propionic acid, and butyric acid, and consequently, decreased the $\mathrm{pH}$. Even though the effects of RPG0136 on all intestinal bacteria were not analyzed, and population variations in other beneficial or harmful bacteria could be considered, Lactobacillus and Bifidobacterium have been shown to enhance the production of SCFAs and lower intestinal $\mathrm{pH}$. Therefore, we surmised that RPG0136 may increase the intestinal concentration of SCFAs by promoting the growth of Lactobacillus and Bifidobacterium. SCFAs are closely related to the intestinal immune system; they reduce intestinal permeability and perform various physiological functions [20-23]. Moreover, organic acids, such as acetic acid, propionic acid, and butyric acid, can promote intestinal peristalsis, reduce the fecal retention time in the small intestine, and improve the rate of dispersion of nutrients [24, 25]. SCFAs are a preferred energy source for intestinal cells and are involved in the regulation of cell apoptosis and differentiation [26-28]. Additionally, acetic acid, propionic acid, and butyric acid are known to inhibit histone deacetylase and activate $\mathrm{G}$ proteincoupled receptors. In the intestine, these SCFAs increase the thickness of the mucus layer of the epithelial barrier, regulate cytokine secretion, regulate antibody production by promoting regulatory $\mathrm{T}$ cell proliferation, and affect 

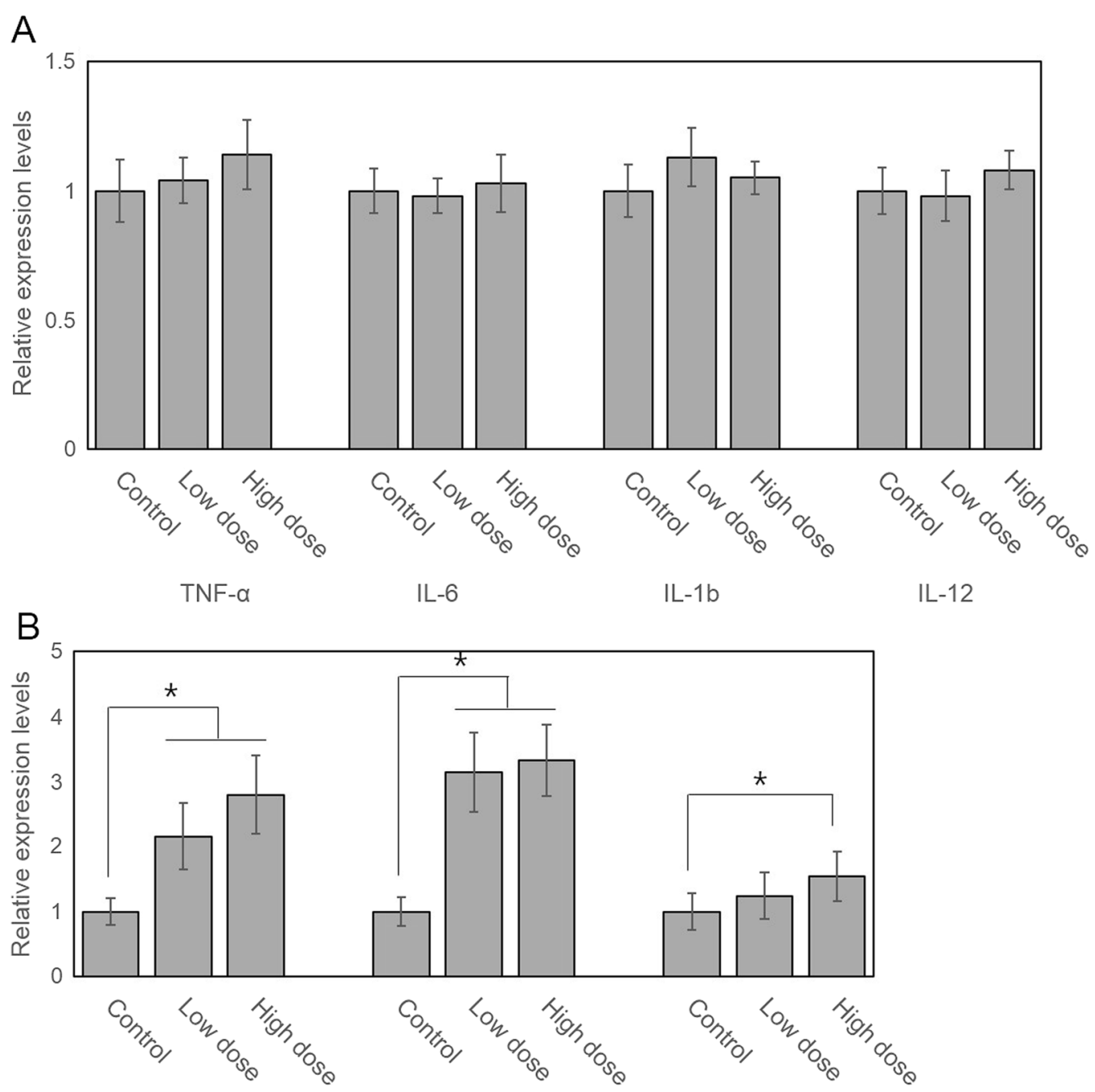

MUC1

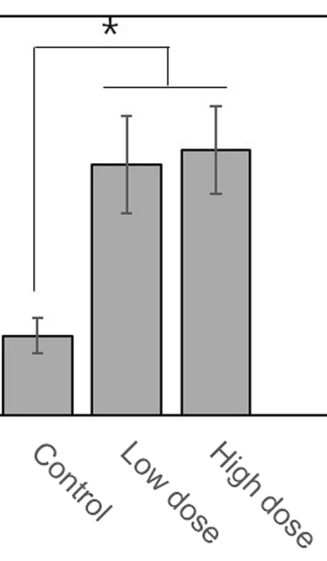

MUC2

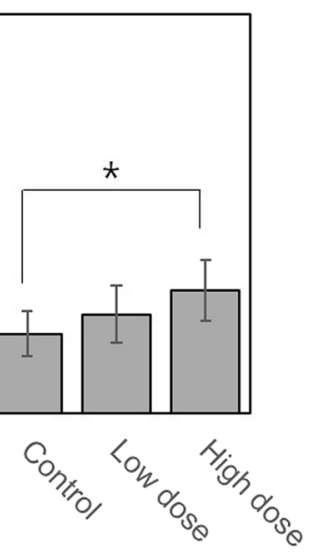

$\operatorname{Reg} 3 g$

Fig. 7 mRNA expression levels of inflammatory cytokines and mucin-encoding genes. The relative mRNA expression levels of (A) TNF-a, IL-6, IL-1 $\beta$, IL-12, (B) MUC1, MUC2, and Reg3r genes were measured and compared after the oral administration of RPG0136 (low-dose: $1 \times 10^{8}$ colony-forming units (CFU)/ml; high-dose: $\left.1 \times 10^{10} \mathrm{CFU} / \mathrm{ml}\right)$. Data are presented as the average value of the results of four independent experiments with standard deviations, ${ }^{*} p<0.05$

immune function by suppressing NF-kB expression [29, 30].

The beneficial effects of probiotic bacteria on the gut and immune function have been widely reported. For example, probiotic bacteria increase the secretion of SIgA, which prevents the invasion of pathogenic bacteria, helps maintain normal bacterial growth in the intestine, and regulates the levels of inflammatory cytokines produced by immune cells, thereby effectively suppressing inflammation and reducing spontaneous physiological hyperimmune or allergic responses [31-33]. In addition, lactobacilli positively modulate the intestinal microflora and immune system and can produce metabolites with anti-inflammatory properties [34]. In particular, Lactococcus lactis, a lactic acid bacterium, is considered as a delivery medium for anti-inflammatory materials in the gastrointestinal tract because of its high muco-adhesion of surface proteins [35].

RPG0136 also increased the plasma IgG and intestinal mucosal SIgA concentrations, which indicates that similar to other probiotics, it may enhance immune function. Notably, RPG0136 upregulated the expression of genes encoding Reg3r, MUC1, and MUC2, which play significant roles in the regulation of intestinal mucosal immune function. MUC1 and MUC2 participate in the production of mucin, a major component of the intestinal mucosal 
barrier that protects the intestinal barrier at the forefront of intestinal immunity [36]; MUC1 is a membrane-bound type, mainly involved in intestinal innate immunity, and specifically binds to the surface of pathogenic bacteria, effectively preventing them from entering the body [37, 38]. MUC2 is a secretory mucin that exhibits viscosity and possesses a gel-like bonding structure that creates a physical barrier to prevent the entry of pathogenic bacteria $[35,36]$. Reg3r is evenly distributed in the intestinal mucosal membranes and is known to exert a strong antibacterial effect by protecting and strengthening the intestinal barrier and preventing the passage of intestinal microflora. In addition, Reg3r has been reported to improve the symptoms of inflammatory bowel disease [39]. Considering that all three proteins protect the intestine biologically or physically against pathogens or small particles, their upregulation, mediated by RPG0136 administration, is most likely related to the improvement of intestinal mucosal immune function.

In conclusion, we demonstrated that the newly isolated RPG0136 strain exerts the following probiotic effects: (1) promotes the dominance of certain beneficial bacteria over harmful bacteria, (2) increases the production of SCFAs, and consequently, reduces the levels of odorants and toxic molecules, thereby promoting a healthy intestinal environment, and 3) enhances intestinal mucosal immune function. In future studies, we intend to focus on various applications of RPG0136 for intestinal immunity-related therapeutics, foods related to functional improvement, and development of feed additives for the livestock industry.

\section{Acknowledgements}

Not applicable.

\section{Authors' contributions}

$\mathrm{BHP}$ and $\mathrm{BCL}$ contributed to the writing of the manuscript and performed the majority of data analysis. OWK, JKP and ISK performed experiments and prepared raw materials. HML and ZZ contributed to the discussion of experimental results and data. BCL and BHP planned and led this research. All authors read and approved the final manuscript.

\section{Funding}

This work was supported by grants from the National Research Foundation of Korea (NRF) (2018M3A9F3055925) funded by the Korean government (Ministry of Science, ICT \& Future Planning) to B.C.L.

\section{Availability of data and materials}

All data generated or analyzed during this study are included in this published article.

\section{Declarations}

\section{Competing interests}

The authors declare no competing financial interests. The authors have filed a patent application relating to the technology.

\section{Author details}

1'Department of Biotechnology, College of Life Sciences and Biotechnology, Korea University, Seoul 02841, Republic of Korea. ${ }^{2}$ Raphagen Co., Ltd.
6F Jangmun-Ro, Youngsan-Gu, Seoul 04393, Republic of Korea. ${ }^{3}$ HealingBio Co., Ltd. Worok-Ri, Hyeundo, Cheongju, Chungbuk 42640, Republic of Korea. ${ }^{4}$ Department of Biochemistry, Morrissey College of Arts and Science, Boston College, Boston, MA 02467, USA. ${ }^{5}$ Department of Toxicology, School of Public Health, Xinxiang Medical University, 601 JinSui Rd, Xinxiang, Henan, China.

Received: 2 November 2021 Accepted: 14 December 2021

Published online: 24 December 2021

\section{References}

1. Holo H, Nes IF (1989) High-frequency transformation, by electroporation, of Lactococcus lactis subsp. cremoris grown with glycine in osmotically stabilized media. Appl Environ Microbiol 55:3119-3123

2. Khine WWT, Haldar S, De Loi S, Lee YK (2021) A single serving of mixed spices alters gut microflora composition: a dose-response randomised trial. Sci Rep 11:11264

3. Zhai Y, Yang J, Zhang J, Yang J, Li Q, Zheng T (2021) Src-family protein tyrosine kinases: a promising target for treating cardiovascular diseases. Int J Med Sci 18:1216-1224

4. Fan Y, Pedersen O (2021) Gut microbiota in human metabolic health and disease. Nat Rev Microbiol 19:55-71

5. Wen L, Duffy A (2017) Factors influencing the gut microbiota, inflammation, and type 2 diabetes. J Nutr 147:1468S-1475S

6. Alcock J, Maley CC, Aktipis CA (2014) Is eating behavior manipulated by the gastrointestinal microbiota? Evolutionary pressures and potential mechanisms. BioEssays 36:940-949

7. Belizario JE, Napolitano M (2015) Human microbiomes and their roles in dysbiosis, common diseases, and novel therapeutic approaches. Front Microbiol 6:1050

8. Shin JM, Gwak JW, Kamarajan P, Fenno JC, Rickard AH, Kapila YL (2016) Biomedical applications of nisin. J Appl Microbiol 120:1449-1465

9. Ahire JJ, Dicks LM (2015) Nisin incorporated with 2,3-dihydroxybenzoic acid in nanofibers inhibits biofilm formation by a methicillin-resistant strain of Staphylococcus aureus. Probiotics Antimicrob Proteins 7:52-59

10. Karakas Sen A, Narbad A, Horn N, Dodd HM, Parr AJ, Colquhoun I, Gasson MJ (1999) Post-translational modification of nisin. The involvement of NisB in the dehydration process. Eur J Biochem 261:524-532

11. Wiedemann I, Breukink E, van Kraaij C, Kuipers OP, Bierbaum G, de Kruijff B, Sahl HG (2001) Specific binding of nisin to the peptidoglycan precursor lipid II combines pore formation and inhibition of cell wall biosynthesis for potent antibiotic activity. J Biol Chem 276:1772-1779

12. Delves-Broughton J, Blackburn P, Evans RJ, Hugenholtz J (1996) Applications of the bacteriocin, nisin. Antonie Van Leeuwenhoek 69:193-202

13. Severina E, Severin A, Tomasz A (1998) Antibacterial efficacy of nisin against multidrug-resistant Gram-positive pathogens. J Antimicrob Chemother 41:341-347

14. Cleveland J, Montville TJ, Nes IF, Chikindas ML (2001) Bacteriocins: safe, natural antimicrobials for food preservation. Int J Food Microbiol 71:1-20

15. Hartemink R, Rombouts FM (1999) Comparison of media for the detection of bifidobacteria, lactobacilli and total anaerobes from faecal samples. J Microbiol Methods 36:181-192

16. Lee JH, Lee HY, Cho D, Kim MJ, Jung JG, Jeong EH, Haque MA, Cho KM (2021) Biodegradable properties of organophosphorus insecticides by the potential probiotic Lactobacillus plantarum WCP931 with a degrading gene (opdC). Appl Biol Chem. https://doi.org/10.1186/ s13765-021-00632-3

17. Yamamoto-Osaki T, Kamiya S, Sawamura S, Kai M, Ozawa A (1994) Growth inhibition of Clostridium difficile by intestinal flora of infant faeces in continuous flow culture. J Med Microbiol 40:179-187

18. Ravishankar S, Maks ND, Teo AY, Strassheim HE, Pascall MA (2005) Minimum leak size determination, under laboratory and commercial conditions, for bacterial entry into polymeric trays used for shelf-stable food packaging. J Food Prot 68:2376-2382

19. Rajalingam N, Yoon JH, Yoon B, Hung NB, Kim WI, Kim H, Park BY, Kim SR (2021) Prevalence and molecular characterization of Escherichia coli isolates during radish sprout production in the Republic of Korea. Appl Biol Chem. https://doi.org/10.1186/s13765-021-00597-3 
20. Mortensen PB, Clausen MR (1996) Short-chain fatty acids in the human colon: relation to gastrointestinal health and disease. Scand J Gastroenterol Suppl 216:132-148

21. Kang CH, Kim JS, Park HM, Kim S, Paek NS (2021) Antioxidant activity and short-chain fatty acid production of lactic acid bacteria isolated from Korean individuals and fermented foods. 3 Biotech 11:217

22. Koh A, De Vadder F, Kovatcheva-Datchary P, Backhed F (2016) From dietary fiber to host physiology: short-chain fatty acids as key bacterial metabolites. Cell 165:1332-1345

23. Vinolo MA, Rodrigues HG, Nachbar RT, Curi R (2011) Regulation of inflammation by short chain fatty acids. Nutrients 3:858-876

24. Morrison DJ, Preston T (2016) Formation of short chain fatty acids by the gut microbiota and their impact on human metabolism. Gut Microbes 7:189-200

25. van de Wouw M, Boehme M, Lyte JM, Wiley N, Strain C, O'Sullivan O, Clarke G, Stanton C, Dinan TG, Cryan JF (2018) Short-chain fatty acids: microbial metabolites that alleviate stress-induced brain-gut axis alterations. J Physiol 596:4923-4944

26. Wang J, Friedman EA (1998) Short-chain fatty acids induce cell cycle inhibitors in colonocytes. Gastroenterology 114:940-946

27. Yang W, Yu T, Huang X, Bilotta AJ, Xu L, Lu Y, Sun J, Pan F, Zhou J, Zhang W, Yao S, Maynard CL, Singh N, Dann SM, Liu Z, Cong Y (2020) Intestinal microbiota-derived short-chain fatty acids regulation of immune cell IL-22 production and gut immunity. Nat Commun 11:4457

28. Ratajczak W, Ryl A, Mizerski A, Walczakiewicz K, Sipak O, Laszczynska M (2019) Immunomodulatory potential of gut microbiome-derived shortchain fatty acids (SCFAs). Acta Biochim Pol 66:1-12

29. Lee J, Venna VR, Durgan DJ, Shi H, Hudobenko J, Putluri N, Petrosino J, McCullough LD, Bryan RM (2020) Young versus aged microbiota transplants to germ-free mice: increased short-chain fatty acids and improved cognitive performance. Gut Microbes 12:1-14

30. Rivera-Piza A, Lee SJ (2020) Effects of dietary fibers and prebiotics in adiposity regulation via modulation of gut microbiota. Appl Biol Chem. https://doi.org/10.1186/s13765-019-0482-9

31. Tlaskalova-Hogenova H, Stepankova R, Hudcovic T, Tuckova L, Cukrowska B, Lodinova-Zadnikova R, Kozakova H, Rossmann P, Bartova J, Sokol D, Funda DP, Borovska D, Rehakova Z, Sinkora J, Hofman J, Drastich P, Kokesova A (2004) Commensal bacteria (normal microflora), mucosal immunity and chronic inflammatory and autoimmune diseases. Immunol Lett 93:97-108

32. Ren D, Gong S, Shu J, Zhu J, Rong F, Zhang Z, Wang D, Gao L, Qu T, Liu H, Chen P (2017) Mixed Lactobacillus plantarum strains inhibit staphylococcus aureus induced inflammation and ameliorate intestinal microflora in mice. Biomed Res Int 2017:7476467

33. Soldi S, Tagliacarne SC, Valsecchi C, Perna S, Rondanelli M, Ziviani L, Milleri S, Annoni A, Castellazzi A (2019) Effect of a multistrain probiotic (Lactoflorene((R)) Plus) on inflammatory parameters and microbiota composition in subjects with stress-related symptoms. Neurobiol Stress 10:100138

34. Celiberto LS, Bedani R, Rossi EA, Cavallini DC (2017) Probiotics: The scientific evidence in the context of inflammatory bowel disease. Crit Rev Food Sci Nutr 57:1759-1768

35. Mercier-Bonin M, Chapot-Chartier MP (2017) Surface proteins of Lactococcus lactis: bacterial resources for muco-adhesion in the gastrointestinal tract. Front Microbiol 8:2247

36. Sheng $Y H$, Hasnain SZ, Florin TH, McGuckin MA (2012) Mucins in inflammatory bowel diseases and colorectal cancer. J Gastroenterol Hepatol 27:28-38

37. Xu Q, Sun LP, Wang BG, Liu JW, Li P, He CY, Yuan Y (2013) The co-expression of functional gastric proteins in dynamic gastric diseases and its clinical significance. BMC Clin Pathol 13:21

38. Machado JC, Nogueira AM, Carneiro F, Reis CA, Sobrinho-Simoes M (2000) Gastric carcinoma exhibits distinct types of cell differentiation: an immunohistochemical study of trefoil peptides (TFF1 and TFF2) and mucins (MUC1, MUC2, MUC5AC, and MUC6). J Pathol 190:437-443

39. Loonen LM, Stolte EH, Jaklofsky MT, Meijerink M, Dekker J, van Baarlen $P$, Wells JM (2014) REG3gamma-deficient mice have altered mucus distribution and increased mucosal inflammatory responses to the microbiota and enteric pathogens in the ileum. Mucosal Immunol 7:939-947

\section{Publisher's Note}

Springer Nature remains neutral with regard to jurisdictional claims in published maps and institutional affiliations.

\section{Submit your manuscript to a SpringerOpen ${ }^{\circ}$ journal and benefit from:}

- Convenient online submission

- Rigorous peer review

- Open access: articles freely available online

- High visibility within the field

- Retaining the copyright to your article

Submit your next manuscript at $\boldsymbol{\nabla}$ springeropen.com 